\title{
FERROL (1878-1915)
}

\author{
M. ${ }^{a}$ Eva Ocampo Vigo \\ I.E.S. Rodolfo Ucha Piñeiro, Ferrol. \\ evaoca@terra.es
}

Para entender mejor cómo Ferrol fue capaz de mantener una vida cultural y social tan animada y con un nivel de actuaciones en las que estuvieron presentes las mejores compañías que actuaron en España, es necesario explicar que esta ciudad tuvo momentos de gran auge económico, lo que favoreció todo tipo de diversiones. Si bien es verdad que también tuvo momentos de precariedad, por la importancia que tenía dentro de Galicia (había sido la primera ciudad gallega en número de habitantes y en estos treinta y seis años que recoge el estudio, era la segunda, después de A Coruña), siempre estuvo incluida en las giras que las compañías hacían por Galicia.

La importancia de Ferrol proviene de una singularidad: desde su moderna concepción dieciochesca, ha sido una población creada por el Estado para el servicio del Estado. En la ciudad se construían barcos para la Marina de Guerra y los periodos de auge o crisis de la ciudad coinciden con los de la constructora, según exista mayor o menor carga de trabajo. 
En la tesis Las representaciones escénicas en Ferrol: 1879-1915 (en proceso de publicación), de la que soy autora, entre otros capítulos, se dedicó uno al estudio de las distintas compañías que visitaron esta ciudad. Así, se puede comprobar que fueron 151 grupos profesionales los que representaron en los escenarios ferrolanos durante los treinta y seis años que abarca esta investigación. La mayoría de las compañías que nos visitaron no fueron de primer orden, sin embargo, un buen número de ellas eran compañías profesionales que, procedentes en su mayor parte de Madrid, llegaban a la ciudad precedidas de fama.

Así ocurre con las compañías que a continuación reseñaremos; todas ellas formadas por primeras figuras de prestigio en su momento y trayendo un repertorio de moda, prestigiado por éxitos en otras ciudades en donde ya habían representado.

Siguiendo el orden de mayor número de obras representadas en nuestros escenarios, las diez compañías profesionales más importantes que actuaron en Ferrol fueron:

\section{LA COMPAÑÍA DE ZARZUELA EMPRESA ARTÍSTICA DE PABLO LÓPEZ}

Esta compañía había visitado Ferrol en mayo de 1885, actuando en el Teatro Circo tres días; puso en escena seis obras; había gustado tanto que los periódicos anunciaron llenos completos en cada puesta en escena, aunque el teatro tenía sólo un aforo de 440 localidades. Entre sus componentes venía la primera actriz Alemany y los actores Pablo López, Blanquells y Lacarra.

Las obras que representaron en esta breve visita fueron, entre otras, la zarzuela La tempestad, de Ramos Carrión y Chapí y la opereta $E l$ duquecito, de Lecoq y Auber; fue precisamente esta última la que más gustó al público ferrolano, sobre todo por la música.

Siete años más tarde, en 1892, es inaugurado en Ferrol otro teatro, el Jofre, y con la ilusión de echarlo a andar trayendo a sus escenarios compañías de primer orden, lo inaugura la compañía dramática de Antonio Vico y cuando ésta remata sus actuaciones, inmediatamente continúa la ya conocida Compañía de Zarzuela de Pablo López.

En esta segunda visita la compañía ofrece veinte funciones de abono, que una vez finalizadas se prolongan con otras nueve fuera 
de abono, debido al apoteósico éxito que tuvo entre los ferrolanos. Esta vez los componentes que forman el elenco son más famosos; vienen las actrices Eulalia González (ferrolana), Amelia López, Las Santas y los actores J. Beltrami, Mariano Guzmán, J. Lacarra y el admirado actor Pablo López, entre otros.

La compañía trae un repertorio amplio, de 41 obras. Al no poder enumerar todas, debido a la amplitud exigida a este estudio, citaremos las que tuvieron más éxito entre los ferrolanos: la revista $D e$ Madrid a París, de J. Veyán, Sierra y Chueca; las zarzuelas Las hijas de Eva, de Luis M. de Larra y Gaztambide; El rey que rabió, de Ramos Carrión, V. Aza y Chapí, con escenografía del célebre Muriel, y que a petición del público fue repuesta cuatro veces; el drama lírico La choza del diablo, del celebrado Ramón Ramírez, que venía precedido de grandes éxitos cosechados en el Teatro de la Zarzuela de Madrid. El molinero de Subiza, La bruja, El anillo de hierro y La tempestad fueron otras zarzuelas representadas por la Compañía de Pablo López.

Al año siguiente, en mayo de 1893, la compañía de Pablo López volvía a representar en el teatro Jofre. Esta vez sólo abrió un abono por seis funciones y otra más, en honor a la escuadra inglesa, para la que representó totalmente en francés Le roi à ranger. En total representó catorce obras. Los periódicos de la época destacaron que algunas de ellas lucirían decorados del pintor madrileño José del Barco, como así fue en la representación de Los sobrinos del Capitán Grant y Mis Helyett (El Correo Gallego, n. ${ }^{\circ} 4.394,3 / 5 / 1893$, p. 2).

Vuelve la compañía en 1901, y permanece durante los meses de marzo y abril en la ciudad. Va a representar diecinueve obras de abono, siendo la puesta en escena de Electra fuera del mismo. Las representaciones vuelven a tener lugar en el teatro Jofre.

Esta vez ocurre la desgracia de que un componente de la compañía, el maestro concertador Juan García Catalá, muere y al estar casado con una ferrolana, Carmen Paz, se realizan las exequias en la ciudad. El teatro Jofre es cubierto de negro porque la comitiva fúnebre pasará por delante; allí se detendrá, mientras la orquesta y coros de la compañía entonan un responso.

Los periódicos hacen una semblanza del compositor cuyo último triunfo había tenido lugar en el teatro Price de Madrid con el estreno de La campana milagrosa, de Marcos Zapata. Una hija del maestro fallecido fue la notable actriz Concha Catalá, que perteneció a la compañía 
de García Ortega, con la que estrenó Los galeotes, en el teatro de la Comedia de Madrid.

La compañía vuelve a su trabajo inmediatamente después del entierro, representando la zarzuela religiosa El milagro de la Virgen, que será interpretada por los actores con un lazo de crespón negro en el brazo izquierdo, mientras en el teatro había una atmósfera de tristeza $\mathrm{y}$ respeto.

A pesar del éxito de público y de crítica obtenido siempre por esta compañía en la ciudad, uno de los críticos ferrolanos más exigentes, Tannhâuser, resumía así su opinión sobre ella:

Al escribir nuestras revistas hemos tratado con benevolencia a la compañía de Pablo López con objeto de animar a todos los artistas para que se esmerasen en complacer al público, pero este estímulo fue ineficaz: los cantantes descuidaron muchas obras que podian haber tenido más unidad y colorido, aun no teniendo medianas facultades algunos de los intérpretes (El Correo Gallego, n. ${ }^{\circ} 6.404,13 / 12 / 92$, p. 2.).

También se le reprochaba a la compañía que los entreactos eran siempre muy largos. Por eso, otro crítico ferrolano, Ferrer Mata, parodiando a Chueca en La caza del oso, remató un día su comentario de esta manera:

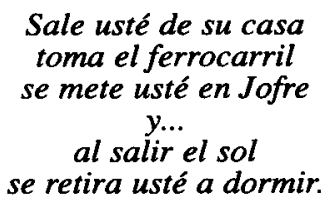

\section{COMPAÑ̃́A DE ZARZUELA DE MAXIMINO FERNÁNDEZ}

El barítono Maximino Fernández y la compañía de zarzuela que dirigía visitaron la ciudad en la Cuaresma de 1879 , prolongando su estancia hasta mayo. Abrió un abono por ocho únicas representaciones.

Entre los componentes de la compañía, además de su director Maximino Fernández, venía el director en funciones, Luis Carceller y 
Dolores Perlá, Juan Maristany, Hermenegildo Gaya y José Bosch; también le acompañaban veinte coristas de ambos sexos. La figura más esperada era la primera tiple absoluta, Carmen Ruiz.

Las obras que pusieron en escena fueron: Sueños de oro y El barberillo de Lavapiés, de Larra y Barbieri; Marta, adaptación de M. del Palacio y E. Álvarez; Las campanas de Carrión, de Luis Mariano de Larra y música de Robert Planquette; El anillo de hierro, de Zapata y Marqués y El loco de la guardilla, de Narciso Serra, entre otras.

A pesar de que el teatro presentaba asiduamente el aforo completo se protestó desde los periódicos porque el coliseo estaba a oscuras y los pocos quinqués que funcionaban impregnaban de olor a gasolina a las personas que ocupaban las primeras butacas.

El periódico El Anunciador de La Coruña, siempre en disputa para demostrar que en aquella ciudad sabían más de teatro que en Ferrol, publicó una nota intentando avergonzar a su colega ferrolano, que hacía muy buena crítica de la compañía en una de sus representaciones y asegurando que en la ciudad vecina habían tenido grandes éxitos:

Le engañaron. Nuestro apreciable colega «El Correo Gallego», periódico de El Ferrol, dice que ha obtenido en La Coruña un gran éxito la zarzuela de espectáculo «Sueños de oro», puesta en escena por la compañía que dirige D. Maximino Fernández.

El éxito ha sido el siguiente: con respecto al decorado, medianejo, pues una parte de los telones fueron los que posee nuestro coliseo, pintados por el Sr. Luccini y que tanto llaman la atención. Es fácil que algún espectador hubiera aplaudido la decoración de casa pobre, creyéndola nueva. La ejecución de la obra, como de ensayo. La concurrencia en la primera noche no fue un lleno completo, en la segunda 300 personas y la tercera, un velatorio. ¿Se llama a esto alcanzar gran éxito? (El Correo Gallego, n. ${ }^{\circ} 200$, $30 / 3 / 1879$, p. 2 ).

El Correo Gallego, después de cruzar varias cartas con el periódico de La Coruña remató el tema pidiendo más prudencia a los coruñeses que les pasaron la información.

De todas formas la compañía de Maximino Fernández gustó tanto que fue invitada de nuevo a representar en la ciudad por segunda vez, este mismo año de 1879 , en agosto. Las representaciones tendrían lugar en el teatro Circo, acabado de inaugurar. Consiguieron un abono muy numeroso y éxitos diarios. 
Entre los componentes figuraban las actrices Adela Rodríguez, María Terrer de Fernández y Carmen Ruiz y los actores José Bosch, Luis Bonoris, H. Gaye y P. Constanti.

Entre las obras que representaron citaremos: Juan de Urbina y Sueños de oro, de Larra y Barbieri (esta última había sido representada anteriormente en el antiguo teatro, el Principal, de manera extractada); De Madrid a Biarritz, de Ramos Carrión, Carlos Coello y Arrieta; El anillo de hierro, de Marcos Zapata y música de Marqués; La marsellesa, de Ramos Carrión y Fernández Caballero; Zampa o La esposa de mármol, de Narciso Serra y Miguel Pastorfido; Los diamantes de la corona, de Camprodón y Barbieri; Sueños de oro y El barberillo de Lavapiés, de Luis Mariano de Larra y Barbieri.

En febrero de 1883 esta misma compañía de zarzuela volvía a Ferrol, trayendo como primera tiple a la ferrolana Eulalia González además de los actores Senis, Beltrán y Alcaide.

Se pusieron en escena 34 obras, entre las que destacamos: La guerra santa, de Pérez Escrich, Luis M. de Larra y Arrieta; El anillo de hierro, de Marcos Zapata y Marqués; La tempestad, de M. Ramos Carrión y Chapí (en el anuncio de esta zarzuela se destacaba que todo el decorado de la obra fue pintado expresamente por los artistas Bussato y Bonardi); Las dos princesas, de $\mathrm{M}$. Ramos Carrión y Fernández Caballero; Adriana Angot, arreglo de Puente y Brañas y Lecocq; Las dos huérfanas, de M. Pina Domínguez y Chapí; Los sobrinos del Capitán Grant, de M. Ramos Carrión y Caballero; Marina, de F. Camprodón y Arrieta; Música clásica, de Estremera y Chapí.

Entre las críticas que se le hicieron a esta compañía destacamos:

\begin{abstract}
La compañia de Maximino Fernández representó en la ciudad dos zarzuelas de tres actos cada una: «El secreto de una dama», de Luis Rivera $y$ "Estebanillo», de V. de la Vega, Gaztambide y Oudrid. Ambas son dos producciones de las más insignificantes dentro del repertorio español, en ambas se notaba falta de ensayos, aunque no es de extrañar en una compañía que ofrece cada noche una obra distinta; además los actores realizaron actuaciones perfectas y acabadísimas como en la zarzuela «El relámpago», de Camprodón y Barbieri (El Correo Gallego, n. ${ }^{\circ} 382$, $8 / 11 / 1879$, p. 3).
\end{abstract}

Cuando la compañía de Maximino Fernández representó la zarzuela cómica italiana en tres actos, La prova d'una opera seria, arreglada a la escena española por Frontaura, Rivera y Di Franco, con el título de 
Campanone y a beneficio de la primera tiple Carmen Ruiz, la crítica manifestó:

En cuanto a la ejecución, cúmplenos enviar un aplauso a todos los artistas que en ella tomaron parte, por su acierto, distinguiéndose notablemente la tiple Carmen Ruiz que cantó el rondó del tercer acto de un modo admirable, así como a Maximino Fernández y a José Bosch. La ejecución de la obra no dejó nada que desear (El Correo Gallego, n. ${ }^{\circ}$ $325,28 / 8 / 1879$, pp. 2 у 3 ).

\section{COMPAÑía dRAMÁTICA DE ANTONIO VICO}

El día 19 de mayo de 1892 se realizó la inauguración del mejor teatro que tuvo y aún tiene la ciudad de Ferrol, el Jofre. Para tal acontecimiento se contrató a una de las compañías de mayor prestigio del momento en España, como era la compañía dramática de Antonio Vico. Se abrió un abono para realizar veintidós representaciones, una por noche.

Entre los componentes de la compañía venían figuras de prestigio como Antonio Vico, Antonio y Francisco Perrín, Alfredo Cirera y Ramón Vallarino y actrices como Antonia Contreras, Carmen Ortega, Felisa Romero, Rosa Tovar y Concha Morell.

El día de la inauguración la obra escogida fue el drama El alcalde de Zalamea, de Calderón, refundido por Adelardo López de Ayala y el juguete cómico El sueño dorado, de Vital Aza.

Además se representaron obras que fueron escritas expresamente para el primer actor Antonio Vico, como A espaldas de la ley, de José Velilla y Luis Escudero y $O$ locura o santidad y Vida alegre y muerte triste, escritas ambas por José Echegaray pensando en el actor.

Otros autores representados nos informan del carácter clásico de esta compañía; además de Echegaray, pusieron en escena obras de Tamayo: Un drama nuevo y La bola de nieve; Bretón de los Herreros: Un tercero en discordia; Vital Aza: Los tocayos, La ocasión la pintan calva, etc.

Los periódicos anunciaron reiteradamente que para la inauguración del teatro Jofre la empresa utilizaría el alumbrado de gas para poder ver las funciones sin dificultades. 
Cuando en mayo de 1898 llega nuevamente a Ferrol la compañía de Antonio Vico para representar en el teatro Jofre, la prensa hizo escaso eco de su visita, más pendiente de las noticias que llegaban de Cuba.

Entre los componentes venían las actrices Ramona Valdivia, Emilia Torrecilla y Concepción Bermejo y los actores Antonio, José y Manuel Vico y Enrique Jiménez. Representó sólo cinco obras, aunque estuvo afincada en Ferrol diecisiete días, posiblemente representando en ciudades vecinas. Las obras seguían perteneciendo a un repertorio serio, como fueron El alcalde de Zalamea, de Calderón y Más vale maña que fuerza, de Tamayo; Consuelo, de Adelardo López de Ayala; Caerse de un nido, de Echegaray y Juan José, de Dicenta. La compañía de Vico no tuvo esta vez tanto éxito como en su primera visita. Los tiempos habían cambiado para Ferrol, que se veía inmersa en la contienda ultramarina; los marinos ferrolanos eran enviados a Cuba de donde llegaban heridos, si no habían muerto en la isla o en la travesía; las pagas no se cobraban y la ciudad estaba sumida en la tristeza y la desolación.

La razón de esta apatía parece ser que no sólo se da en Ferrol, sino que es general. Un comentario del año 1898, realizado por el crítico teatral ferrolano que firmaba como B. Iga, nos aclara esta situación; decía textualmente:

En Ferrol contamos con tres coliseos y los tres vegetan en eterna clausura [...] Hay que levantar el ánimo adormecido a los embates del nacional infortunio [...] Para la América del Sur tomaron contrata y soleta no una ni dos docenas de compañías, sino brigadas enteras del híbrido género zarzuelesco y del legendario declamatorio, huyendo de la quema. [...] Emigra la Guerrero a París, en busca de horizontes que ve cerrados en la propia casa; sigue Vico idénticos derroteros dejando aquí a España con sus tragedias y yéndose con sus dramas él. Cual última trinchera se defienden en La Comedia la Cobeña, Thuillier, Donato Jiménez y Cuevas [...] y ni con un candil hallan las empresas de provincias un punto a donde dirigir los ojos por escasez de personal para organizar una compañia presentable. El arte de la guerra mató el arte del teatro y si no lo mató lo ha trastornado por completo (El Correo Gallego, n. ${ }^{\circ} 6.872,18 / 10 / 1898$, p. 1).

En mayo de 1899 la compañía dramática de Antonio Vico se encontraba de nuevo en la ciudad, en donde la situación económica y social había mejorado en parte. La compañía fue recibida con cariño y en esta ocasión tuvo mucho éxito de crítica y público en sus representaciones.

En el elenco figuraban las actrices Ramona Valdivia, Emilia Torrecilla, Micaela Calle y Concepción Bermejo y los actores Antonio, José y Manuel Vico, Alejandro Garrido, José Portes y Enrique Jiménez. 
Representaron en el teatro Jofre diecinueve obras, entre las que destacaron El amor y el interés, de Mariano de Larra; Lo sublime en lo vulgar, El gran Galeoto, Vida alegre y muerte triste, de Echegaray; Un tercero en discordia, de Bretón de los Herreros; Traidor, inconfeso y mártir, de Zorrilla; Los amantes de Teruel, de Harzenbuch y El noveno mandamiento, de José Vico.

Los críticos de los periódicos prodigaron diariamente elogios a la compañía y, sobre todo, a su primer actor, José Vico.

La empresa del teatro puso a disposición del Capitán General de la Octava Región Militar un palco de proscenio para que lo utilizase con su Estado Mayor, mientras se encontrase en Ferrol, atención que hizo extensible al Ministro de Marina, que también se hallaba en la ciudad. La función de gala se realizó de acuerdo con el Ministro para que pudiese estar presente. Posteriormente éste solicitó un palco para todas las noches mientras permaneciese en Ferrol.

Los elogios que le profesaban los críticos teatrales a la compañía decían:

Albricias merece el eminente Vico por el fervoroso culto que rinde a las letras españolas, ofreciéndonos ocasión de admirar y aplaudir las joyas del teatro nacional, ya antiguo, ya moderno (El Correo Gallego, n. ${ }^{\circ} 7.051$, 26-5-1889, p. 2).

Satisfechísimo salió de la fiesta el selecto concurso que pasó deliciosamente las horas de la velada y recompensó el talento de los artistas con repetidas salvas de aplausos y llamadas al palco escénico (El Correo Gallego, n. ${ }^{\circ} 7.051,26-5-1899$, p. 2).

Sin embargo, en la capital de España algunos críticos ya predecían el futuro de Vico; alguno decía con ensañamiento:

Vico está en decadencia. Es un anciano irrespetable [...] como actor es una mala persona y como persona un mal actor (Charivari, «Vico», La Campaña, 18/2/1898).

Sin embargo, en Ferrol el público, aunque reconocía que Vico envejecía, opinaba que seguía siendo uno de los mejores actores de la época. Así lo dejó plasmado en sus versos el poeta local B. Iga, que dedicó a Antonio Vico un largo poema a sus virtudes como persona y sobre todo como dramaturgo. Recogemos los primeros versos: 


\author{
A VICO \\ Eres de la dramática española \\ lo bueno que nos queda, \\ y con razón te llama todo el mundo \\ hoy el rey de la escena; \\ no porque estés «tronado» porque el tiempo \\ ni aun al genio respeta, \\ no hay en pecho de artista consumado \\ corazón que envejezca.
}

(El Correo Gallego, n. ${ }^{\circ}$.051, 26-5-1899, p. 2).

\title{
4. LA COMPAÑÍA DE JUAN CATALINA
}

Cuando se hacían los preparativos para inaugurar en Ferrol el teatro Circo, que sería el 11 de julio de 1879, se pensó en traer para tal acontecimiento a una de las compañías de prestigio que actuaban en nuestro país, la compañía de Maximino Fernández. Sin embargo, no pudo ser por estar dicha compañía cumpliendo compromisos en otras localidades. Por este motivo, la inauguración del teatro corrió a cargo de la compañía dramática de Juan Catalina, que no desmerecía en nada de la anterior, como lo había demostrado en los meses de abril y mayo, de este mismo año, en los que ya había actuado en Ferrol.

La primera vez que visitó la ciudad fue en abril de 1879 y trabajó en el teatro Principal. En esta ocasión la compañía iba a representar dieciséis obras, en diez funciones de tarde y noche.

En el elenco destacaban figuras como José Barta, Eduardo Fraile y sobre todo el mismo director, Juan Catalina; las actrices Amalia Losada, Amelia Fernández Lozano y Dolores Estrada. Las obras que pusieron en escena fueron: La ley del mundo, de Mariano Pina; A primera sangre, de Matoses; El pañuelo blanco, de Blasco; Vivir al día, de Liern y Un novio a pedir de boca, de Bretón de los Herreros, entre otras.

La segunda vez que esta compañía vuelve a Ferrol fue para la inauguración del teatro Circo, el 11 de julio de 1879. Permanecieron en la ciudad veinte días y representaron veintiocho obras. El estreno se realizó con la puesta en escena de El tanto por ciento, de Adelardo López de Ayala y La partida de ajedrez, de González de Iribarren. Se realizó una exhibición general de todas las decoraciones, obra del escenógrafo Vielsa. Este día concurrieron al teatro 1.200 personas, 
cuando el aforo era de 1.104 localidades; en este año el censo de población en Ferrol era de 24.000 habitantes.

Otras obras representadas fueron La resurrección de Lázaro, de Enrique Gaspar; La careta verde, de Ramos Carrión; El hombre de mundo, de Ventura de la Vega; Consuelo, de Adelardo López de Ayala, etc.

Uno de los días se anunció en los periódicos la comedia de gracioso La sombra de Torquemada, de Antonio Bermejo, pero el mismo día fue suspendida la función por medio de una nota publicada en $E l$ Correo Gallego que decía escuetamente «hoy no habrá función en el teatro Circo» 1 .

\section{LA COMPAÑÍA DE MARIANO DE LARRA Y BALAGUER}

Esta compañía actuó en el teatro Jofre en noviembre de 1901, abriendo un abono para representar treinta y tres obras. Entre sus componentes venían las señoras Rafaela Lasheras, Sofía Romero y Elvira Pardo y los actores Balaguer (Juan y Manuel) y Mariano Larra. Uno de los críticos teatrales más veraces de la época, José Martínez Ruiz (1982: 179), consideraba que Mariano de Larra era uno de los mejores actores cómicos del momento. Así lo comprendieron en Ferrol, agasajándolo en cada una de sus representaciones.

Las obras que más éxito de público tuvieron fueron las comedias $E l$ oso muerto, El sombrero de copa y El señor cura, de Vital Aza; La victoria del general y El patio, de los hermanos Quintero; el juguete cómico Los asistentes, de Pablo Parellada y El rey de Lydia, de Merino.

Los ferrolanos llenaron todos los días las localidades del teatro; la crítica periodística reafirmaba cada día el buen hacer de los componentes de la compañía. Extraemos un comentario aparecido en $\mathrm{El}$ Correo Gallego:

El cuadro de la compañía es completo, acabado y muy igual, mereciendo las simpatías que el público les demuestra. Dadas las merecidísimas sim-

${ }^{1}$ Parece que la censura tuvo que ver en esta decisión, aunque nada de ello trascendió al público. 
patías que se ha captado el Sr. Balaguer, es de constatar que el teatro se vea tan concurrido y que el público corresponda como es de justicia a los méritos de tan celebrado y aplaudido artista (El Correo Gallego, n. ${ }^{\circ}$ $7.849,15 / 11 / 1901$, p. 2).

\section{LA COMPAÑía CÓMICO-DRAMÁTICA DE MARÍA ÁLVAREZ TUBAU}

Visitó la ciudad durante diez días de enero de 1893, representando dieciocho obras.

Estaba dirigida por Ceferino Palencia y llegaba de Madrid. En su repertorio traía obras de autores franceses como Alejandro Dumas, del que puso en escena La dama de las camelias y Frou-Frou, pero también El sueño dorado, de Vital Aza; Batalla de damas, de López Fortún, etc. Entre sus componentes gozaban de popularidad las actrices Emilia Domínguez, Consuelo Badillo y, sobre todo, María Á. Tubau; entre los actores el más aplaudido en Ferrol fue Sala-Julién.

Se dio la circunstancia que la compañía se disolvió después de la última representación en Ferrol, pues «la Tubau» marchaba a París a encargar trajes lujosos ya que en breve comenzaría una gira por el extranjero; el resto de los componentes quedaron unos días deambulando por la ciudad.

En el mes de junio de 1903 visitó de nuevo la ciudad la compañía cómico-dramática de la Tubau, dirigida por Ceferino Palencia; procedían de La Coruña. En Ferrol actuaron en el teatro Jofre, abriendo un abono para ocho funciones. Realizaron doce representaciones, destacando entre su repertorio, como la vez anterior, obras de autoría francesa: Francillón, La dama de las camelias, Frou-Frou, de Alejandro Dumas; Divorciémonos y La corte de Napoleón, de Victoriano Sardou.

Como venían de gira por Galicia tuvieron la deferencia de representar la obra del autor gallego Linares Astray, Aires de fuera, que, al igual que en La Coruña, resultó un éxito de crítica y público.

En esta visita parece que la compañía no levantó los entusiasmos de la primera vez. En 1893 las críticas que aparecieron en los periódicos de la época eran laudatorias para la primera actriz, como comprobamos en la extraída de El Correo Gallego de ese año: 
Sobre la compañía de Ceferino Palencia cuando representó «La dama de las camelias" con notable éxito; fue muy aplaudida María Álvarez Tubau mientras que los demás artistas cumplieron bien (El Correo Gallego, $\mathbf{n} .^{\circ}$ 4304, 11-1-93, p. 2).

Pero en 1903 las cosas habían cambiado y, en consecuencia, los comentarios críticos también:

Sobre la compañía de Ceferino Palencia se escribe:

[...] la mayor parte de las obras representadas no fueron del agrado del público, unas por malas, otras por fósiles, y otras, «La corte de Napoleón», de V. Sardou, por ejemplo, porque en ellas hay una rica propiedad escénica que, aunque aquí no fue mala, bastó para explicar el éxito que esas obras han obtenido en otros teatros. No hay en esta compañía nada más que una figura que destaque: la de la señora Tubau; todas las demás son muy modestas, a excepción del joven Llano, del cual creemos que, estudiando mucho, pueda llegar a valer (El Correo Gallego, n. ${ }^{\circ} 8.475,17 / 6 / 1903$, p. 2).

Sin embargo, el crítico —anónimo— lanza un irónico aviso a la primera actriz:

La Tubau sabe mejor que nosotros que hay un tiempo preciso, determinado, para retirarse airosamente de las lides artisticas. Los ocasos son hermosos, más fascinadores que la brillante luz del mediodía, pero son muy breves (El Correo Gallego, n. ${ }^{\circ} 8.475,17-6-1903$, p. 2).

\section{LA COMPAÑÍA DE COBEÑA-THUILLIER}

Esta compañía actuó en Ferrol en varias ocasiones, siempre con gran éxito de crítica y público, como correspondía a la categoría de los componentes de la misma. Entre ellos, se encontraban Josefina Blanco (la futura mujer de Valle-Inclán) y los propios Carmen Cobeña y Emilio Thuillier.

La primera vez que representó en la ciudad fue en mayo de 1901; estaba dirigida por Thuillier. En esta ocasión ofrecieron ocho funciones de abono, siendo todas las representaciones del drama Electra, de Galdós, fuera de abono. Aunque los precios fueron caros - cinco pesetas la butaca y cuatro la de abono- el teatro presentó todos los días el aforo completo. 
Entre las diecinueve obras que representaron fueron las más aplaudidas: los dramas Fedora, de V. Sardou y Mancha que limpia, de J. Echegaray; las comedias El tanto por ciento, de A. López de Ayala o El bajo y el principal, de F. Villegas y La de San Quintín, de Galdós. Anunciaban decorados nuevos en la mayoría de las obras.

En el estreno de Electra, el público que ocupaba las localidades más baratas, las de paraíso, hizo tanto jaleo que el crítico teatral publicó el siguiente suelto en la prensa:

\begin{abstract}
Un ruego al Sr. Alcalde:
Es preciso ordene a sus delegados que sostengan a toda costa el orden en las alturas del teatro. Ya se pagó el tributo a la actualidad tolerando las expansiones con motivo de la representación de "Electra», y es preciso que el buen nombre y la cultura jamás desmentida de nuestro pueblo, quede en el lugar que le corresponde, demostrándose que un día es un día, pero no todo el año (El Correo Gallego, n. ${ }^{\circ} 7.474,13 / 5 / 1901$, p. 2).
\end{abstract}

En octubre de 1908, la compañía de Carmen Cobeña, dirigida esta vez por Francisco Oliver, volvió de nuevo a la ciudad para realizar un abono de cinco funciones con siete representaciones. El teatro presentaba llenos rebosantes.

Entre los componentes de la compañía figuraban las actrices Josefina Álvarez y Carmen Cobeña y el actor Ricardo Manso. Los precios resultaron muy caros para el público: butaca por abono, 20 pesetas y sin él 25 , por lo que la empresa, a petición de los abonados, rebajó las localidades.

Las obras puestas en escena fueron: Los ojos de los muertos y Señora ama, de J. Benavente; La vida que vuelve y La escondida senda, de los hermanos Quintero; La ñoña, de Oliver y La madre, de Rusiñol. Las actrices Carmen Cobeña y Carmen Bustamante y los actores Francisco Comas y Ricardo Manso fueron los más aplaudidos. El teatro siempre estuvo repleto de público.

\title{
8. LA COMPAÑía DRAMÁTICA DE EMILIO MARIO
}

Esta compañía actuó en Ferrol en el mes de mayo de 1887, representando once obras en el teatro Romea. 
En los periódicos locales se quejaban de que no representen en el teatro Circo «más amplio, más cómodo y en cuya escena no hubieran tropezado con las dificultades con que luchaban ayer, porque [...] no cabían los personajes de la obra en escena». Pero el teatro Circo estaba en venta para ser demolido.

El repertorio que representaron estaba formado, en su mayoría, por obras francesas: Dora y Fernanda, de V. Sardou; Felipe Derblay, de G. Ohuet; Mr. Alphonse, de A. Dumas; además de Lo positivo.

Entre los actores fueron admirados en la ciudad los famosos Emilio Mario y Mendoza Tenorio; entre las actrices, Elisa Mendoza Tenorio, Carmen Valero y Sandoval.

De nuevo se vuelve a producir en la ciudad un accidente entre los miembros de una compañía; el día 19 de mayo, cuando la compañía se desplazaba unos días a Lugo y La Coruña para realizar unas representaciones mueren en un accidente de carretera un actor y un transeúnte en la localidad coruñesa de Alvedro. La compañía vuelve a Ferrol para cumplir sus compromisos, pero solo representará una obra en el teatro Circo, la comedia Lola, de Enrique Gaspar. Los precios de las localidades fueron altos: 20 pesetas los palcos sin entrada, ya que el producto, 8.000 reales, se destinó íntegro a la familia del actor La Hoz.

Las críticas a esta compañía fueron muy cariñosas:

La despedida que [...] dio nuestro público a la compañía del eminente actor Emilio Mario fue cariñosisima; una ovación de entusiasmo, un tributo de admiración al genio, y una muestra de las generales simpatías que tan renombrados artistas alcanzaron con su breve estancia en Ferrol (El Correo Gallego, n. ${ }^{\circ} 2.507,28 / 5 / 1887$, p. 2).

En la segunda quincena de abril de 1894 vuelve a presentar sus actuaciones la compañía de Emilio Mario López en el teatro Jofre de Ferrol. En esta ocasión trae entre sus componentes a figuras de la talla de María Guerrero (que va a formar compañía y empresa propia este mismo año), Sofía Alverá, Josefina Blanco (la futura esposa de Valle-Inclán) y Concepción Ruiz; entre los actores aparecen en la lista Luis Romea (al que no se hace referencia en los días sucesivos), García Ortega, Juan Balaguer, Alfredo Cirera y Miguel Cepillo. Pusieron en escena catorce obras, entre las que destacaron por su éxito La loca de la casa y La de San Quintín, ambas de Benito P. Galdós, y Mariana, de Echegaray; La 
huelga de hijos, de Enrique Gaspar; Militares y paisanos, arreglo de Emilio Mario hijo y Zaragüeta, de Ramos Carrión y Vital Aza.

Sobre la compañía de Emilio Mario en el estreno de Mariana, de Echegaray, un autor dramático, del que no se cita el nombre, decía textualmente en el periódico local:

Entre las seis $u$ ocho obras dramáticas que he visto representar, desde que tengo uso de razón, de una manera perfecta, ésta es una de ellas (El Correo Gallego n. ${ }^{\circ} 4.688,19 / 4 / 94$, p. 2).

Otro comentario sobre la compañía de Emilio Mario señalaba:

Goza de una gran fama su cuadro artístico. En los corrillos de los entreactos se comentaba que la compañía tenía arte, estudio, cariño por la escena, y el eminente Mario que la cuidaba en todos sus detalles, haciendo resaltar todos los valores artísticos de la obra (El Correo Gallego n. ${ }^{\circ}$ $4.686,17 / 4 / 94$, p. 2 ).

Según el crítico teatral de $E l$ Correo Gallego, los comentarios que se oían por los pasillos del Jofre no podían ser más entusiastas y halagadores para los artistas de la compañía:

¡Ésta es compañía [...] Aquí hay arte, estudio, cariño por la escena y el eminente Mario que la cuida en todos sus detalles pude estar satisfecho del acierto con que es secundado.

Es inútil repetir a diario que el público sale tan satisfecho [...] como espera de la justa fama de que viene precedida la compañía.

[...] El público continúa asistiendo con verdadera complacencia al coliseo (El Correo Gallego n. ${ }^{\circ} 4.686,17 / 4 / 94$, p. 2 ).

\section{LA COMPAÑÍA DEL TEATRO LARA DE MADRID, DIRIGIDA POR JULIÁN ROMEA}

En junio de 1886 estuvo actuando en el teatro Romea la compañía del teatro Lara de Madrid. Representó durante veinticuatro días, en los que puso en escena veinticuatro obras. 
Entre sus componentes venían las actrices Balbina Valverde, Gorriz, Romero y Romea DElpas y los actores Romea, Tamayo, Galván y Romea D'Elpas; con ellos venía Ruiz de Arana, el que sería uno de los mejores actores de su época, según el crítico José Martínez Ruiz (1982: 179).

En sus actuaciones representaron, entre otras, las comedias $L a$ mamá política, de Ramos Carrión; Perecito, de Vital Aza; los apropósitos Día completo y Moros en la costa, de Eusebio Blasco; los juguetes Pobres hombres, Los martes de los Gómez y El reverso de la medalla, de Mariano Barranco; Caerse de un nido y En plena luna de miel, de Echegaray; Política interior, de Flores García; Vivir para ver, de Sánchez Pastor; La almoneda del tercero, de Ramos Carrión y Vital Aza y Niña Pancha, de Constantino Gil y música de Julián Romea y Valverde.

También se representó un monólogo titulado La noche antes, escrito expresamente para Julián Romea por Javier Cavestany.

La ciudad de Ferrol respondió diariamente con llenos completos, hasta el punto que en El Correo Gallego salió una nota de reconocimiento de la compañía al afecto mostrado por los ferrolanos. Decía:

\begin{abstract}
El ilimitado reconocimiento de esta compañia por la afectuosa acogida que se ha servido dispensarle el cultísimo público ferrolano, le impone, el no por obligado, menos grato deber de rendir un testimonio de los profundos sentimientos de reciprocidad con que corresponde a deferencia tanta [...] por lo que dedicará las funciones próximas al imperecedero recuerdo que lleva de sus distinguidos favorecedores (El Correo Gallego, n. ${ }^{\circ} 2.291,16 / 6 / 1886$, p. 3 ).
\end{abstract}

Por su parte, el periódico se deshacía, día a día, en alabanzas a Julián Romea, al que denominaba como «el mejor de los actores españoles».

\title{
10. LA COMPAÑíA DE MARÍA GUERRERO
}

El anuncio de la llegada de esta compañía a la ciudad fue gran motivo de alegría; los ferrolanos ya conocían a la actriz María Guerrero de cuando había estado en Ferrol con la también famosa compañía dramática de Emilio Mario, en abril de 1894. En aquella ocasión los 
ferrolanos ya supieron reconocer los valores dramáticos de semejante figura.

La compañía de la eminente actriz y de su esposo Díaz de Mendoza permaneció en la ciudad entre junio y julio de 1902 por espacio de seis días, abriendo un abono por seis funciones y poniendo en escena un total de once obras. El precio de los palcos fue de 21 pesetas.

Entre los componentes de la compañía destacaban, además de la primera actriz María Guerrero y su esposo Fernando Díaz de Mendoza, las actrices Encarnación Bofil, Concepción Ruiz, Matilde Baena, María Cancio y Cecilia Coy; entre los actores se encontraban Enrique Barragán, Felipe Carsi, Alfredo Cirera, Ramón Guerrero y Antonio Manchón.

Las obras representadas fueron: Lo positivo y Locura de amor, de Tamayo; La cuerda floja y El otro, de Estremera; El estigma, Malas herencias y El loco Dios, de Echegaray; A cadena perpetua, de José M. a García; La mujer de Loth, de Sellés; La pecadora, de Guimerá y Mi misma cara, de Pina Domínguez.

El público ferrolano demostró, en todo momento, su simpatía por la compañía en general, pero, sobre todo, por su primera actriz, María Guerrero. Durante las representaciones se sucedieron las notas periodísticas que elogiaban la excelsa labor de la diva. Recogemos alguna de ellas:

\begin{abstract}
Momentos hubo en que los gritos y el entusiasmo del auditorio adquirieron la nota de una verdadera aclamación que la actriz supo agradecer con deferente galantería cantando en gallego un precioso a-la-lá, en el que puso todas las ternuras de nuestros melancólicos cantos y todo el sentimiento y delicadeza con que María sabe enaltecer cuanto interpreta con su exquisita conciencia artística. Los aplausos del público fueron delirantes [...] (El Correo Gallego, n. ${ }^{\circ} 8.087,7 / 7 / 1902$, pp. 1-2.).
\end{abstract}

Para concluir, tenemos que aclarar que Ferrol, aún en sus peores momentos económicos, tuvo una animada actividad teatral y los ferrolanos, paradójicamente, llenaban los teatros cuando una compañía de prestigio representaba en ellos. En años de crisis, como fueron a partir de 1904, en que había hambre y movilizaciones de los obreros de la constructora, no sólo siguieron llegando compañías teatrales a la ciudad (aunque no fuesen todas de fama nacional), sino que, en septiembre de 1906, se inaugura otro teatrillo, el pabellón New-England, que junto con el Jofre y el Romea, que seguían funcionando, aseguraban la celebración de espectáculos en Ferrol. 


\section{FUENTES CONSULTADAS}

\subsection{Prensa}

El Correo Gallego (1878-1915).

La Monarquía (números sueltos de 1886 a 1893).

\subsection{Bibliografía}

Caldera, Ermanno y Calderone Antonietta (1988). «El teatro en el siglo XIX (I) (1808-1844)». En Historia del teatro en España, II. Siglo XVIII y XIX, José M. ${ }^{\mathrm{a}}$ Díaz Borqué (ed.), 377-624. Madrid: Taurus.

Clemente Cubillas, Enrique (1984). Desarrollo urbano y crisis social en Ferrol. Universidad de Salamanca: Colegio Oficial de Arquitectos de Galicia.

COTARELO Y MORI, Emilio (1934). Historia de la zarzuela o sea el drama lírico en España, desde su origen a finales del siglo XIX. Madrid: Tipografía de Archivos.

GarCía LoRenzo, L. y EsPín TemPLADo, M. P. (1998). «El teatro durante la restauración y el fin de siglo: El teatro menor». En Historia de la literatura española. Siglo XIX (II), García de la Concha (ed.) y Romero Tobar (coord.), tomo 9, 132-142. Madrid: Espasa Calpe.

Espín Templado, M. a Pilar (1987). «El sainete del último tercio del siglo XIX: culminación de un género dramático histórico en el teatro español». Epos III, 97-122.

GaYoso, Justo (1909). «La vida moderna en Ferrol y su comarca». En $A l$ manaque de Ferrol para el año 1910, coleccionado por Leandro de Saralegui y Medina, 70-76. Ferrol: Imprenta de El Correo Gallego.

IgLeSIAS DE SouzA, Luis (1991). Teatro lírico español. Tomo I. Coruña: Excma. Diputación de A Coruña.

- (1993). Teatro lírico español. Tomo II. A Coruña: Excma. Diputación de A Coruña.

- (1995). Teatro lírico español. Tomo III. A Coruña: Excma. Diputación de A Coruña.

- (1996). Teatro lírico español. Tomo IV. A Coruña: Excma. Diputación de A Coruña.

LORENTE DE CASTRO, José (1998). «Aquellos tiempos de la zarzuela (II)» en la revista Ferrolanálisis (Ferrol: Club de Prensa), abril, n. ${ }^{\circ} 12,90-97$. 
MARTínez RuIz, J. (1898). «Del teatro en Madrid». La Campaña (19/1).

PIÑEIRO DE SAN Miguel, Esperanza (1997). La guerra de Cuba vista desde Ferrol (1895-1898). Ferrol: Edicións Embora.

Romera Castillo, José (1993). «Teatro regional español del siglo XIX (Bibliografía)». En Ex libris. Homenaje al profesor José Fradejas Lebrero. José Romera et alii (eds.), volumen II, 705-718. Madrid: UNED. - (2000). «Una bibliografía (selecta) para la reconstrucción de la vida escénica española en la segunda mital del siglo XIX». Signa, 9, 259421 (también en formato electrónico: http://cervantesvirtual.com/ hemeroteca/signa/).

RUBio JiMÉNEZ, Jesús (1982). Ideología y teatro en España: 1890-1900. Zaragoza: Departamento de Literatura de la Universidad/Libros Pórtico.

VV.AA. (1985). Catálogo de obras del teatro español del S. XX. Madrid: Fundación Juan March.

- (1986). Catálogo de obras del teatro español. Siglo XIX. Madrid: Fundación Juan March.

- (1993). Catálogo de libretos españoles, siglos XIX y XX. Madrid: Fundación Juan March.

YXART, José (1896). El arte escénico en España. Barcelona: Imprenta de La Vanguardia, tomo II. [Reedición en Barcelona: Alta Fulla, 1987, 2 vols.] 